\title{
La reinvención de la autenticidad en el contexto de la mercantilización neolihberal
}

JOSÉ MANUEL RODRÍGUEZ VIGTORIANO" MARINA REQUENA I MORA"

\section{Resumen}

Desde las últimas décadas del siglo pasado, la constatación empírica de que los límites naturales al crecimiento estaban siendo traspasados (García, 2004) supuso un incremento de la conciencia medioambiental y dio lugar a la búsqueda de respuestas de distinto tipo. El concepto de 'Parque Natural', como un intento de preservar determinados espacios, se inscribe en este contexto. En su versión neoliberal dicha preservación no implica ninguna modificación sustantiva de las reglas que impone el desarrollo económico capitalista. De este modo, se convierte en una aplicación del binomio "desarrollo sostenible", un oxímoron (Latouche, 2006) donde se yuxtaponen dos significados contrapuestos, a saber, desarrollo económico capitalista y sostenibilidad medioambiental. En el presente artículo analizamos, en primer lugar, las implicaciones teóricas del concepto 'Parque Natural'. Posteriormente, a partir de las investigaciones realizadas en el parque natural de 'La Albufera de Valencia' (España) reflexionamos sobre los límites y posibilidades de dichos espacios. Tras un análisis somero de la imagen publicitaria del área de reserva natural del 'Tancat de la Pipa' situado en La Albufera, presentamos, posteriormente, las representaciones sociales sobre dicho hábitat producidas mediante entrevistas abiertas y grupos de discusión en cada uno de los sectores sociales implicados. Así vemos, como en los sectores tradicionales el área de reserva natural del Tancat es percibida como una expropiación de su propio espacio; por su parte, los técnicos medioambientales la perciben como un objeto de consumo educativo y científico y, los movimientos ecologistas, como una zona

\footnotetext{
* Universitat de València,Valência, Espanha.

** Universitat de València,Valência, Espanha.
} 
"re-naturalizada" que va acorde con la lógica "desarrollista". Y por último, para el sector caracterizado como 'consumidores de la modernización' el Tancat se concibe como un espacio de consumo 'natural' que a modo de parque temático' se vincula con el ocio familiar.

Palabras clave: Sociología del consumo. Ecología política. Investigación cualitativa. Análisis crítico del discurso.

\section{The reinvention of authenticity in the context of neoliberal commodification}

\section{Abstract}

Since the last decades of the past century, the empirical evidence of the natural limits to growth being overstepped (Garcia, 2004) supposed an increase in environmental awareness and led to a search for answers of different kinds. The concept of 'Parque Natural' (Natural Park) is registered in this context as an attempt to preserve certain areas. In its neoliberal version, such preservation doesn't involve any substantive changes to the rules imposed by the capitalist economic development. Thus, this term becomes an application of the binomial "sustainable development", an oxymoron (Latouche, 2006) which juxtaposes two opposite meanings in global terms, and often, in local terms: capitalist economic development and environmental sustainability. In this paper we analyze, in the first place, the theoretical implications of the concept 'Natural Park'. Subsequently, based on our research in the Albufera of Valencia (Spain) and one of its natural reserve areas, "El Tancat de la Pipa", we present the limits and possibilities of these spaces. The analysis of the discourses, produced through interviews and discussion groups, contextualizes the social representations of this habitat according to their connection with the different social sectors and unravels the meaning given to this area. For the traditional sectors, "El Tancat de la Pipa" is perceived as an expropriation of their land. For the environmental technicians, the area represents an object of educational and scientific consumption. For the ecology movements, it is a "renaturalized" area which is in keeping with the developmentalism. And finally, for the modernization consumers, this zone means a place for consumption that should receive 'more marketing' and be transformed into a "theme park" for family leisure.

Keywords: Consumption sociology. Political ecology. Qualitative research. Critical discourse analysis. 


\section{La politización y la mercantilización de la naturaleza: los parques naturales un oxímoron bien avenido}

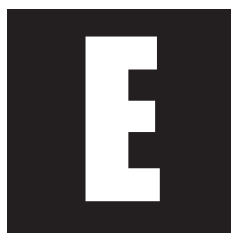

n estos años iniciales del siglo XXI se están acumulando voces que, a partir de datos y esquemas conceptuales no siempre coincidentes ${ }^{1}$, emiten un mismo mensaje: la civilización industrial ha entrado en una fase de translimitación, en la que los límites naturales al crecimiento han sido ya traspasados (Garcia, 2004). La conciencia de que la crisis ecológica es cada vez mayor y la búsqueda de alternativas ha conducido a respuestas de distinto tipo. Muchas de estas respuestas están enmarcadas dentro de las políticas neoliberales que concilian desarrollo económico y sostenibilidad y, de esta manera, se escamotea el conflicto ecológico latente. Entre estas soluciones está el establecimiento de determinados espacios en los que se pretende preservar la naturaleza. El concepto de Parque Natural comparte con él de desarrollo sostenible, su condición de oxímoron (Latouche, 2006). Veámos, etimológicamente, Parque hace referencia a un espacio cerrado y acotado al cual se le imponen límites reales y simbólicos. Además viene marcado, por la actividad recreativa desarrollada en el mismo (Santamarina, 2009). Dicho significado 'parque' — que evoca a algo artificial— se enfrenta al de natural — que evoca, justamente, a lo contrario- $y$, pasa por alto la compatibilidad de ambos objetivos y la disonancia cognitiva (Festinger, 1957) que la unión de ambos términos puede provocar.

De acuerdo con Beltrán, Pascual y Vaccaro (2008), la patrimonialización de la naturaleza, la proliferación de figuras de protección ambiental

\footnotetext{
${ }^{1}$ Estudios tales como los diversos informes del Club de Roma, Living Planet Report, el Pico
} del Petróleo... 
que apela la existencia de un legado común en nuestro entorno que hay que preservar, se debe analizar desde una doble perspectiva. En primer lugar, los espacios naturales, en tanto que instancias sociopolíticas, surgen en determinados lugares, se conforman en base a intereses específicos y tienen efectos constatables a nivel local. Y en segundo lugar, si bien apoyan su legitimación en un discurso de carácter científico-técnico, los parques y las reservas naturales traducen e instituyen una particular concepción cultural acerca de la naturaleza y de las relaciones que las sociedades humanas deben establecer con ella. La declaración de un área protegida supone no sólo una nueva organización y apropiación de los recursos sino también una redefinición del espacio. La expropiación de un espacio que se vive como propio a través de una imposición percibida como ajena y las distintas resistencias puestas en marcha frente a las declaraciones parecen repetirse en muchas de las aéreas protegidas estudiadas a lo largo de la geografía mundial. Por otra parte, las legislaciones suelen partir de la dicotomía naturaleza/cultura y esta oposición supone un tipo de negación que no queda en un mero carácter simbólico de los procesos de apropiación y transformación de los territorios por parte de sus habitantes sino que va más allá y niega también el derecho a decidir sobre los territorios que se pretenden proteger (Coca y Quintero, 2006). Por tanto, estos procesos de patrimonialización olvidan que el patrimonio es una construcción social (Prats, 1997) que responde a determinadas concepciones acerca de lo que debe ser preservado y de cómo hacerlo, y en el que hay voces más poderosas que otras. El patrimonio y la tradición se inventan (Hobsbawn y Ranger, 1992) y cumplen una importante función social, política y económica. La selección de determinados espacio naturales, a los que se activa con la declaración de espacio protegido, puede ser tanto fuente de conflicto como oportunidad para recrear las identidades con nuevos elementos o para desarrollar nuevas actividades económicas (Beltran, Pascual y Vaccaro, 2008). 


\subsection{Los parques naturales como objeto de consumo:}

la mercantilización de la naturaleza

Los procesos de patrimonilaización de la naturaleza y la cultura surgen en el marco general de la terciarización de la economía y la globalización neoliberal ${ }^{2}$. En este sentido, más allá de los objetivos medioambientales que se alegan para justificar su creación, los parques y las reservas naturales contribuyen a asignar valores a espacios y recursos marginales, que pasan a incorporarse en el mercado como bienes de consumo, en un proceso de creciente urbanización del espacio rural (Beltran; Pascual; Vaccaro, 2008). En última instancia, como sostiene Santamarina (2009), la protección de estos lugares llevaría a la regulación de la naturaleza a través de formas de mercantilización, es decir, la reduciría a mercancía insertándola en los circuitos del mercado global. El mercado capitalista convierte a la naturaleza en mercancía y una sociedad dominada por la lógica del mercado subordina lo social e incluso lo natural a la obtención del máximo beneficio. Cuando la naturaleza muda a mercancía se crea una marca, se produce, y la gente en y de los países 'ricos' viene a configurar su identidad ambientalista a través de su consumo (West, 2004) en parte gracias a las representaciones mediáticas de ONGs ambientalista (Week, 1999) y a excusiones, viajes y un sin fin de etcéteras. En definitiva, es una forma más de lo que a finales de los años sesenta del siglo XX, el sociólogo español Mario Gaviria, denominó ideología 'clorofila', a saber, una nostálgica visión de la naturaleza que posibilita su comercialización presentándola como un paraíso perdido asequible (Gaviria, 1969, p.59).

\footnotetext{
${ }^{2}$ Sólo en el Estado español, en los últimos 15 años, según los Anuarios de Europarc, los espacios naturales protegidos han crecido de manera exponencial. En 1995 había 465 espacios naturales y ocupaban el 5,75\% del territorio, en 2011 se contabilizan más de 1700 y pasan a ocupar el $27 \%$ del territorio estatal.
} 
En esta línea, Frigolé (2007) describe el consumo de espacios naturales vírgenes y la recreación forzada de lo natural como un síntoma de una reconstrucción de un pasado idílico perdido.

Desde una perspectiva histórica, siguiendo a Fernández Buey y Riechman (1994), este sentimiento romántico de la naturaleza, frecuentemente ruralizante y antindustrial, preñado de aristocrática nostalgia de un mundo virgen es ya constatable entre las clases altas europeas y norteamericanas en la segunda mitad del siglo XIX. Precisamente, la primera reserva natural del mundo se crea en la Francia de Segundo Imperio en 1853-1861 por iniciativa de un grupo de pintores que conseguirá la protección de 624 hectáreas en el bosque de Fontainebleau. Desde su inicio, no se trata tanto de una voluntad de proteger el medio ambiente cuanto de pautas de apropiación estetizante de los paisajes. La declaración de Parque Nacional de Yellowstone, en 1872, comparte este origen, (Burnham, 2000). Más insidiosamente, Yellowstone se convirtió en un modelo para la creación de paisajes virtuales, en forma de parques temáticos junto con los centros comerciales, hoteles internacionales y otros espacios destinados a presentar a los consumidores experiencias genéricas de historias y paisajes desinfectados de indígenas. El pasado, en versión naturaleza prístina, se convirtió en escudo frente a los intensos cambios y en un instrumento para la construcción de identidades (Lowenthal, 1998). Ese pasado "reinventado" - en los términos en los que lo describen Hobsbawm y Ranger (1988) —, que aplicó el modelo de Yellowstone, rápidamente se repitió por todo el oeste de Estados Unidos. A su vez, los parques norteamericanos, sirvieron de modelo para enfatizar los esfuerzos conservacionistas y la expropiación de tierras a los nativos de todo el mundo (Spence 1999, p. 5 citado en West, Igoe y Brockington, 2006). La consagración de la catedral de la Wilderness suponía la protección de espacios naturales para admirar 'en vivo el espectáculo' de la natural na- 
turaleza (Descola 2007), una suerte de museos 'in situ' para preservar un pasado mitificado, intervenido y ennoblecido (Santamarina, 2009).

En una economía globalizada, la identificación del carácter singular del territorio es lo que confiere a los espacios naturales una imagen simbólica y excepcional (Sanz, 2012). Frente a los no lugares (Auge, 1992), a las áreas protegidas se las asocia los atributos de naturalidad, rusticidad y etnicidad y se traslada a sus productos y al propio consumo del lugar. La economía de signos (Lash y Urry, 1994) favorece esta diferenciación territorial y simbólica de su oferta. Los espacios naturales su consumo y el consumo de sus productos y servicios (gastronomía típica, denominación de origen, paseos en barca...) son un letrero de mercancías que es capaz de aumentar las ventas a consumidores descontentos con la producción en serie (García Canclini, 1982).

Así pues, los espacios naturales no solo se reestructuran como centros de consumo sino a su vez, son también consumidos al igual que su identidad (Sanz, 2012).Tal como asegura Xoaquin Rodríguez (2003), la designación de un lugar como espacio protegido no consiste sólo en la replantación y preservación de especies vegetales o animales sino que implica la creación de una imagen cultural. Una composición que puede ser construida como parte de la simbología nacional o local (Lowenthal, 1994); pero, al mismo tiempo, las características de esa imagen hacen de estos espacios lugares aptos para el consumo, se solazan como paisajes a contemplar. Se nos presentan como productores de significados. Como sostiene Urry (1995), la mirada del turista es producida y es consumida. Las imágenes de la naturaleza virgen son esenciales para la transformación de los paisajes de acuerdo con los sueños de turistas, y estos mismos paisajes transformados luego apoyan la producción de más imágenes de tierra salvaje (Brockington et al, 2008 citado en Igoe, 2010). El mito del lugar está relacionado estrechamente con la representación social (Mos- 
covici, 1979) del espacio, tal y como lo ejemplifica Urry (1995) en el estudio de la formación de imágenes de lugar en el Lake District. La llegada de viajeros hace sentir la necesidad de cubrir esa demanda y la touristgaze va trasmutando al lugar. El espacio se modifica en búsqueda de la autenticidad, tanto para satisfacer la mirada estereotipada del turista como del local; es la autenticidad reinventada (Harvey, 1989). Muchos proyectos de conservación se centran en una especie de comercialización de plantas, animales, lugares o pueblos, pero no suelen tener en cuenta los sistemas locales de evaluación. Mientras que las interacciones previas de la población rural con las plantas y los animales eran formas sociales únicas de relacionarse con su entorno, estas plantas y animales con la hegemonía de la valoración económica borran las formas locales de ver y de ser. Algunas especies han pasado de ser poco conocidos o valorados por la población local a ser productos altamente valorados (Vivanco, 2001). La población local y su imagen también se pueden convertir en productos básicos al igual que su propiedad intelectual que se preocupa por su entorno (West, Igoe, Brockington, 2006). Esta mercantilización de la naturaleza a través de la creación de áreas protegidas también altera los derechos de uso de la tierra en general. Concretamente, en muchos casos vemos un mayor control de la élite de los recursos históricos, al tiempo que se produce una a enajenación de la tierra y el mar en lugares que rodean las áreas protegidas y la criminalización de los locales debido a sus prácticas de uso del suelo (West, Igoe y Brockington, 2006) .La abrumadora impresión que deja la creación del área protegida es el acceso restringido y uso de los pueblos rurales a través de la legislación y la privatización. Como sostiene Igoe (2010) grandes áreas del mundo están siendo rehechas de acuerdo con las fantasías de los turistas. La conservación permite la comercialización de los productos básicos y la producción de entretenimiento. De acuerdo con el mismo autor, podemos afirmar que estas asociaciones en- 
tre las empresas y la conservación hacen hincapié en la mercantilización de la naturaleza a través del pago por servicios ambientales y la mitigación de los daños ambientales en un contexto de conservación. Todas estas transformaciones se encuentra en medio de un fortalecido consenso en el que la lógica del mercado y el crecimiento económico es el mejor, si no el único, medio de salvar a la naturaleza y proteger el futuro de nuestro planeta (McAfee, 1999).

\section{El Tancat de la pipa como area de reserva natural en el parque natural de la albufera}

El Parque Natural de La Albufera de Valencia es el contexto del Tancat de la Pipa como fenómeno social total ${ }^{3}$ (Mauss, 1971). La Albufera ${ }^{4}$ es un espacio natural integrado por tres elementos: restinga, marjal y lago. Alrededor de la Albufera se acumula un cinturón de poblaciones ${ }^{5}$, muchas de las cuales forman parte del área metropolitana de Valencia por lo que han experimentado un crecimiento demográfico sin precedentes que ha influido negativamente en el lago.

\footnotetext{
${ }^{3}$ Marcel Mauss en su obra "Essai sur le don" conceptualizó el fenómeno social total. Tras esta conceptualización, el objetivo de la investigación dejaba de ser estudiar los fenómenos como fragmentos aislados sino que los fenómenos tenían que restituir un conjunto donde apareciera la coherencia interna. Nuestra labor es ver los fenómenos de manera completa, es decir, articulando todo aquello concreto como la síntesis de múltiples determinaciones.

${ }^{4}$ La albufera de Valencia es un espacio situado a pocos kilómetros de la ciudad de Valencia: el lago, la marjal que lo rodea, el bosque de la Devesa y su sistema de dunas integran un complejo ecosistema muy valioso desde el punto de vista de la biodiversidad. En 1986, La Albufera de Valencia fue declarada Parque Natural.

${ }^{5}$ El ámbito territorial del Parque se extiende por numerosos municipios de l'Horta Sur- Albal, Alfafar, Beniparrell, Catarroja, Massanassa, Sedaví y Silla-, de la Ribera Baixa- Albalat de la Ribera, Cullera, Sollana, Sueca-, de la Ribera Alta- Algemesí- y por Valencia y las pedanías de Pinedo, El Palmar, El Saler y El Perellonet.
} 
Siguiendo a Rodríguez Victoriano (2002), podemos afirmar que el Parque Natural de la Albufera entraña un conflicto ecológico-social que condensa el conflicto entre crecimiento económico capitalista y degradación ecológica de la sociedad valenciana. Un modelo que podemos definir como hologramático ${ }^{6}$ donde están representadas todas las escalas: físicas, biológicas, históricas y antropo-sociales. Habría que destacar tres dimensiones. En primer lugar, la articulación entre aquello natural y aquello cultural: los procesos históricos que se han dado en la Albufera la convierten en un artefacto cultural y un sistema natural. En segundo término, La Albufera es un signo, histórico y culturalmente, arraigado en la memoria colectiva de la sociedad valenciana ${ }^{7}$. Y en tercer lugar, enfatizar el carácter de Parque Natural. Este hecho intensifica las contradicciones entre productivismo y ecologismo puesto que: por un lado, para que la protección se traduzca en conservación, las prácticas más nocivas tienen que detenerse, cosa que reclama un nuevo modelo organizativo; por otro lado, la conflictividad que comporta la declaración de Parque Natural, para los sectores tradicionales puesto que limita sus prácticas de explotación intensiva del medio ${ }^{8}$. Siguiendo a García y Cabrejas (1997; 1996), los nudos de conflicto y cooperación en la relación entre el desarrollo, las actividades tradicionales y la conservación de la naturaleza en el Parque Natural de la Albufera se representan en la siguiente tabla — que condensa el modelo básico de análisis, siguiendo las categorías de desarrollo, usos sostenibles y conservación.

\footnotetext{
$\overline{{ }^{6} \text { Donde cada uno }}$ de los puntos que componen esa realidad refleja de alguna manera la totalidad del conflicto.

${ }^{7}$ En el imaginario social de los habitantes cercanos al Parque permanecen las imágenes de un paisaje que ha sufrido numerosas transformaciones la intensidad de la degradación de las cuales ha acelerado coincidiendo con el proceso de desarrollo capitalista.

${ }^{8}$ De las 21.120 hectáreas de extensión del Parque, aproximadamente 18.000 son cultivo de arrozales. La riqueza de su suelo ha sido una tentación para las comunidades humanas de su entorno. De las 30.000 hectáreas de laguna que se ha calculado que tenía en época romana,
} 
Cuadro 1. Núcleos de conflicto y de cooperación entre desarrollo, actividades tradicionales y conservación del medio ambiente en el Parque Natural de la Albufera.

\section{NUCLIS DE CONFLICTE I DE COOPERACIÓ ENTRE DESENVOLUPAMENT, ACTIVITATS TRADICIONALS I CONSERVACIÓ DEL MEDI AMBIENT AL PARC NATURAL DE L'ALBUFERA}

\begin{tabular}{|c|c|c|c|c|c|c|c|c|c|c|c|c|c|}
\hline & 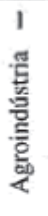 & 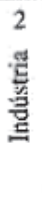 & 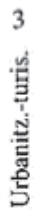 & 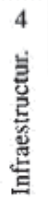 & 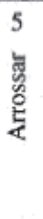 & $\begin{array}{l}6 \\
\text { 屯্ّ }\end{array}$ & $\begin{array}{l}7 \\
\text { Uू } \\
\text { a. }\end{array}$ & 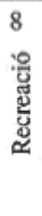 & 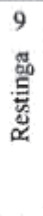 & $\begin{array}{r}10 \\
\text { 嵩 } \\
\end{array}$ & $\begin{array}{l}11 \\
\text { 窝 } \\
\text { 要 }\end{array}$ & 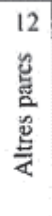 & 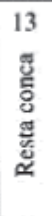 \\
\hline $\begin{array}{l}\text { 1. Agroindústria } \\
\text { 2. Indústria } \\
\text { 3. Urbanització-tur. } \\
\text { 4. Infraestructures } \\
\text { 5. Arrossar } \\
\text { 6. Caça } \\
\text { 7. Pesca } \\
\text { 8. Recreació } \\
\text { 9. Restinga } \\
\text { 10. Llac } \\
\text { 11. Marjal } \\
\text { 12. Altres parcs } \\
\text { 13. Resta conca }\end{array}$ & $\begin{array}{l}* \\
* \\
+ \\
* \\
* \\
* \\
* \\
* \\
* \\
* \\
*\end{array}$ & $\begin{array}{l}+ \\
* \\
*\end{array}$ & $\begin{array}{c}+ \\
* \\
* \\
*+ \\
* \\
* \\
* \\
* \\
* \\
*\end{array}$ & $\begin{array}{l}{ }_{+}^{+} \\
* \\
*_{+} \\
*_{+} \\
{ }^{*}\end{array}$ & $\begin{array}{l}* \\
+\end{array}$ & $\begin{array}{l}* \\
*\end{array}$ & ${ }^{*}+$ & ${ }^{*}$ & $\begin{array}{l}+ \\
+ \\
+ \\
+\end{array}$ & $\begin{array}{l}+ \\
+ \\
+\end{array}$ & $\begin{array}{l}+ \\
+\end{array}$ & + & \\
\hline
\end{tabular}

* indica potencialitat o existència de conflicte

+ indica potencialitat o existència de consens i mutu reforçament

Fuente: García, E. y Cabrejas, M. (1997)

Los puntos del 1 al 4 corresponden al desarrollo convencional. La distinción por sectores se corresponde con la problemática de la zona: modernización de una agricultura dependiente de insumos industriales, expansión industrial, urbanizaciones y servicios turísticos y creación de nuevas infraestructuras. Los puntos del 5 al 8 son los referentes a las actividades tradicionales que han implicado una explotación más o menos sostenible: 
arrozal, caza, pesca y vistas. Los puntos del 9 al 13 hacen referencia a la conservación de la biodiversidad y en general de los valores naturales.

Permanece al imaginario social la idea de una Albufera de aguas cristalinas, de un bien común, patrimonio cultural de naturaleza viva y como tal generador de identidad. Pero a la vez también, este imaginario se impregna de un sentimiento consciente de pérdida, a pesar de que en el inconsciente aparecen las propias prácticas como degradadoras del el estado del lago.

Entonces a la imagen que proyecta ahora la Albufera se le opone esta idea de la Albufera como "paraíso" - lo que los valencianos piensan que fue. Para la sociedad valenciana es siempre por culpa de los otros, de un juego de responsabilidades cruzadas (Garcia, 1997) y también de ese se me'n fotisme ${ }^{9}$ que nos ha caracterizado secularmente, tal como nos definen y a la vez también nos autodefinimos.

Los llamados Tancats de la Albufera son zonas de arrozal nacidas por el aterramiento del lago. El nivel de agua, en este tipo de campos, es controlado por un motor que, cuando es necesario, eleva hasta el lago de la albufera el agua sobrante. Los tancats se ganaron al lago con los históricos aterramientos, que lo hicieron menguar unas 10.000 hectáreas de

las actuaciones de desecación y aterramiento han reducido la extensión lagunar a unas 3.000. Así pues, esta zona húmeda ha estado históricamente afectada por la presión antrópica. Las formas de esta interacción han ido evolucionando con el cambio social. La primera gran afección fue la desecación de gran parte de la superficie lagunar para el cultivo del arroz. Posteriormente, ya en este siglo, al desarrollo agrícola le siguió la localización de un cinturón industrial y poblacional en una época en la que la legislación ambiental en España era prácticamente inexistente. De este modo, a la contaminación producida por la agroindustria del arroz se le sumo toda una serie de efluvios altamente contaminados procedentes de las industrias situadas sobre la antigua carretera nacional N-332. El tercer gran impacto fue el desarrollo de núcleos turísticos de segunda residencia en la franja litoral. Las afecciones comenzaron a controlarse a partir de 1986, fecha de declaración del área como Parque Natural.

${ }^{9}$ Expresión típica valenciana que expresa la indiferencia que los valencianos les damos a las cosas sobre todo a aquello que está relacionado con lo colectivo. Tanto esta denominación como los verbatims que siguen han sido, para facilitar su comprensión, traducidos del valenciano. La lengua en la que se realizaron la mayoría de las entrevistas dado que es la lengua vehicular del País Valenciano, muy arraigada a las comarcas que rodean el lago de la Albufera. 
superficie. Este fenómeno se desarrolló fundamentalmente durante la segunda mitad del siglo XIX y las primeras décadas del XX (Martínez, 2008). El Tancat de la Pipa, concretamente data de 1918. Hace unas décadas, este paraje tenía una gran belleza y conservaba con viveza los ecosistemas de la marjal albuferenca. A partir de los años 70 el espacio empezó a degradarse por la contaminación de las aguas y redujo considerablemente su vegetación y su fauna. El año 2007 empezó a gestarse el proyecto de Restauración de Hábitats para el Uso Público en la Desembocadura del Ilamado Barranco del Poyo. La zona de actuación abrazaba 40 hectáreas. A modo de experiencia piloto se pretendía la recuperación de los hábitats naturales, mediante el aislamiento de la gestión hídrica, de un tancat, que a su vez está interconectado con el lago y el resto de campos de arroz de la zona. La finalidad de las actuaciones era la ejecución de una serie de obras tendentes a la recuperación de los ambientes húmedos y a la mejora de la calidad de las aguas, mediante la instalación de un sistema de filtros verdes que reduce la carga de nutrientes. La dirección de esta Área de Reserva ${ }^{10}$ va a cargo de la a la Confederación Hidrográfica del Júcar $(\mathrm{CHJ})$, su gestión se encomendó a TRAGSA y a la sociedad Acció Ecologista AGRÓ. La actividad investigadora se realiza con diferentes entidades ${ }^{11}$.

\footnotetext{
${ }^{10}$ En el Plan Rector de Uso y Gestión del Parque Natural de la Albufera se estable la definición, possibles usos, así como los usos prohibidos de las zonas que que se establecen como Áreas de Reserva dentro del Parque. Estas zonas tienen una mayor protección que el resto del Parque y por tanto los usos son más restringidos. En las zonas catalogadas como Áreas de Reserva quedan prohibidas las actividades de caza, pesca, cultivo, ganadería...e incluso el tránsito de personas no autorizadas. El uso de estos espacio se limita ( o muta) al estudio e investigación. ${ }^{11}$ La Sociedad Española de Ornitología- seguimiento de aves, estación de aislamiento, etc-; el Instituto Cavanilles de Biodiversidad y Biología Evolutiva de la Universitat de València- estudia y hace un seguimiento limnológico; análisis químico-biológico e identificación taxonómica del plancton- ; el Instituto de Ingeniería del agua y Medio ambiente de la Universitat Politècnica de València - análisis físico-química del agua y sedimento - ; el Instituto Agroforestal del Mediterráneo- seguimiento de poblaciones de artrópodos- y la Facultad de Ciencias Sociales de la Universitat de València- percepción y participación social; programa de sensibilización e implicación de las organizaciones sociales en el entorno del parque de la Albufera.
} 
La actividad didáctica se desarrolla dando a conocer la importancia de este espacio en la conservación de los ecosistemas palustres.

\subsection{La imagen publicitaria del Tancat de La Pipa}

El Tancat de la Pipa, objeto de este trabajo, revive la imagen de la Albufera como paraíso, esto es, rellenada: de asprella ${ }^{12}$, de gambeta ${ }^{13}$, de samaruc $^{14}$, de anguila y desde hace poco tiempo de galápagos y flamencos... y tantos otros elementos simbólicos que configuran la cosmogonía valenciana tan descrita y escrita, y tan aceptada como imagen feliz e idílica. Aunque Blasco Ibáñez (1902), Joan Fuster (1993), o mucho antes, ya en el siglo XVIII, Cavanilles, escribían y describían una realidad de este mismo espacio mucho más dura y mísera, sobre todo para los autóctonos, sobre este signo tan arraigado en la memoria colectiva valenciana.

Un breve y superficial análisis estructural de algunos de los carteles publicitarios de esta Área de Reserva - El Tancat de la Pipa — nos pude ser de gran utilidad para ver como esta zona se reestructura como centro de consumo y, a su vez, es también consumida al igual que su identidad.

\footnotetext{
${ }^{12}$ La asprella (Clara vulgaris) es una alga verde que acumula carbonato de calcio sobre su superficie y es indicadora de la abundancia de ión calcio y de bicarbonato disueltos en el agua. Su existencia en los subsuelos lagunares es un indicador del buen estado ambiental del agua. A su vez, l'asprella, supone el inicio de la alimentación de toda una cadena trófica. Las "gambetes" se alientan de asprella, y muchos peces se alimentan de "gambetes". Lo curioso de la investigación fue que tanto los actores tradicionales así como los ecologistas y la comunidad científica estaban de acuerdo en la importancia de la "asprella".

${ }^{13}$ La "gambeta" (Palaemonetes zariquieyi) es un crustáceo endémico de humedales valencianos, muy sensible a la contaminación y ahora difícil de encontrar en el lago. Al igual que la asprella, la gambeta es un buen indicador sobre la buena calidad de las aguas.

${ }^{14}$ El samaruc (Valencia hispanica) es pez actinoptergio nativo de las aguas quietas de la zona de la costa del mar Mediterráneo. Como ocurre con la "gambeta" es una especie que requiere aguas de buena calidad para su reproducción y en general para su existencia. El samaruc se considera en peligro de extinción por la legislación nacional española (Real Decreto 439/1990) y la autonómica
} 


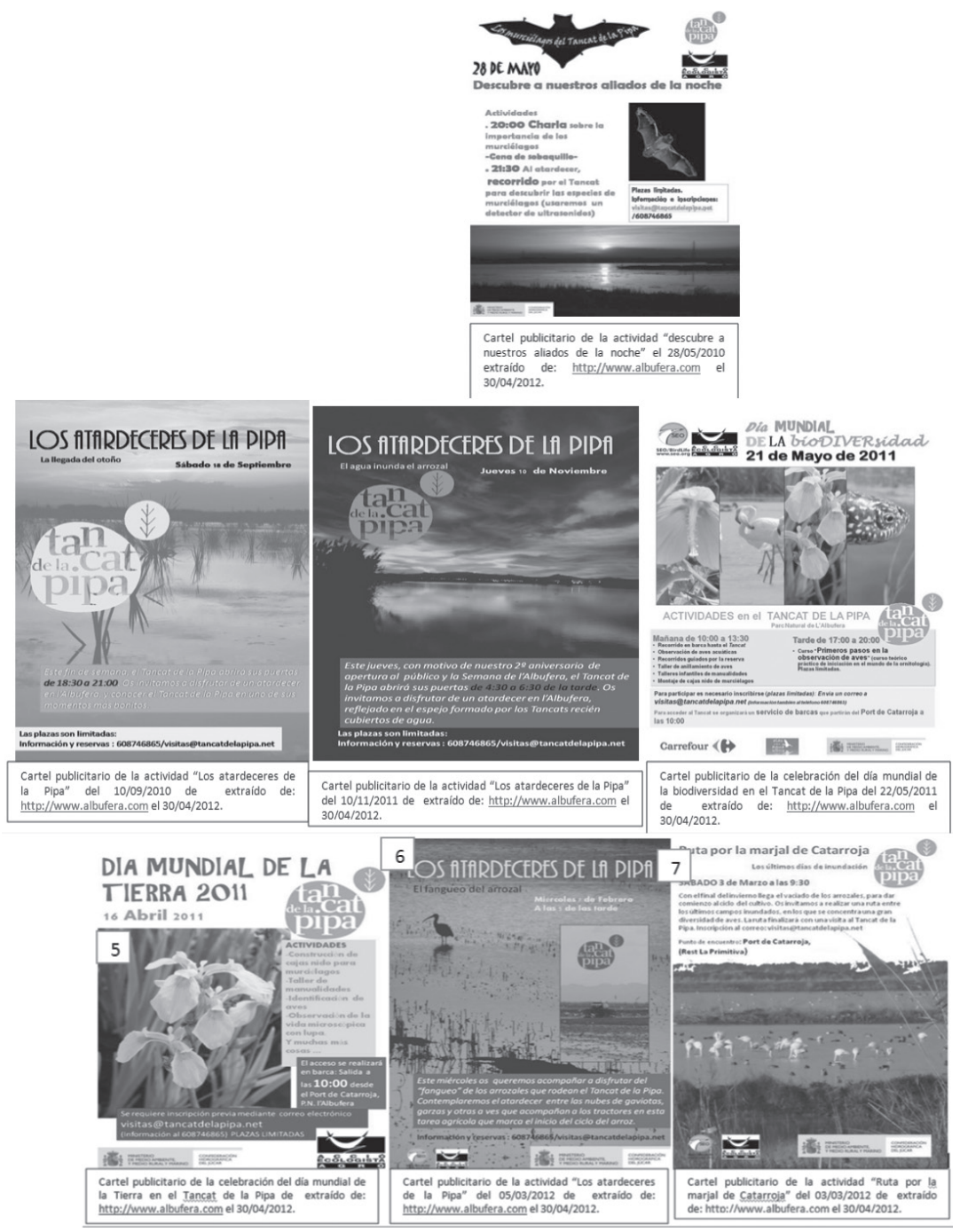

Imágenes 1. Cárteles publicitarios del Área de Reserva del Tancat de la Pipa. 
La necesidad, al menos simbólica, de recuperar l'Albufera, un espacio degrardado pero muy presente en la cosmovición valenciana es evidente. Así mismo también es evidente la necesidad de ofrecer naturaleza, como consecuencia tal vez de la escasez de ella en la ciudad de Valencia y sus alrededores. Gaviria (1969) planeta que, al menos como hipóteisis, la petición de espacios verdes tienen cierto fundamento simbólico, de representación simbólica, una especie de ideología clorofila. Un análisis somero del contenido saca a la luz una serie de temas resumidos a continuación. Las imágenes de los carteles están orientadas a connotar Naturaleza. Se vende naturaleza. Tal y como describía Gaviria (1969) para el análisis de urbanizaciones verdes en Madrid, se vende una nostalgía del paraíso perdido, mezcla bucólico-vegetal. En los carteles, es muy notoiro este énfasis en la connotación bucólico-vegetal, según la qual una romántica idea de estado salvaje, de encanto natural, un terreno no contaminado por la avalancha urbanística, que supone Valencia y su área metropolitana, se utiliza como reclamo. Cada uno de los carteles remite a elementos naturales que se ofrecen para ser observados y consumir la imagen que poryectan; los murcielagos, los flamencos, los lirios, las garzas, los galápagos... y, como no, los atardeceres. Por supuesto, en las imágenes se desvincula la naturaleza de toda acción humana desarrollada en la zona. Como veíamos desde la creación de Yellowstone, la construcción de las áreas protegidas, se basa en una naturaleza sin seres humanos pero para ser visitada, disfrutada y contemplada por seres una humanos donde la única actividad permitida es la turística. De esta manera se olvida la historia social del lugar que hasta hace menos de cinco años era un campo de arroz que datava de 1918. La dualidad naturaleza/cultura se impone en la zona como único modelo interepretativo, se instruye bajo un paradigma que obvia y destruye la diversidad de conciminetos locales que no siguen esta distinción. Las actividades agrícolas aparecen como 
algo secundário y subordinado a la contemplación de la naturaleza. En algunos textos de los cárteles se hace referencia a la actividad del arroz.

Contemplaremos el atardecer entre la nubes de gaviotas, garzas y otras aves que acompañan a los tractores en esta tarea agrícola que marca el inicio del ciclo del arroz (Cartel $n^{\circ} 6$ ). Con el final del invierno llega el vaciado de los arrozales para dar comienzo al ciclo del cultivo del arroz.Os invitamos a realizar una ruta entre los últimos campos inundados en los que se concentra una gran variedad diversidad de aves (...) (Cartel no7).

Pero, tal y como se observa, en ningún momento las actividades se centran en dar a conocer la actividad agrícola sino que está se menciona por el simple hecho de que su existencia altera la cantidad y diversidad de aves.

Esta preponderancia del conocimiento científico técnico sobre el cocimiento local, tan presente en los discursos, también la apreciamos hasta en el propio logo de la zona que está representado por una caña. Precisamente el "cañar" supone ahora uno de los principales conflictos entre técnicos y agricultores e incluso pescadores. A través de los discursos el sector tradicional reitera las críticas hacia los técnicos por la prohibición de la quema de las cañas y de la paja del arroz y por no dar una solución a la pudrición de estas en el lago provocando así una gran mortandad de peces. También los movimientos ecologistas y ciudadanos se han unido en una plataforma ${ }^{15}$ que achaca la mortandad de peces a la

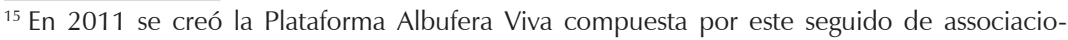
nes: L'Associació de Vela Llatina de Silla, I'Associació Vela Llatina Peixcadors de Catarroja, I'Associació de Vela Llatina de Catarroja, el Club de Vela Llatina del Palmar, la Comunitat de Peixcadors del Palmar, la Comunitat de Peixcadors de Catarroja, la Comunitat de Peixcadors de Silla, la Federació Valenciana de Caça, el Club de Caçadors del Palmar, el Club de Caçadors d'Albalat de la Ribera, I'Associació Ames de Casa TYRIUS del Palmar, el Club de Peixcadors I'Anguila d'Albal, I'Associació Cultural Parc Natural I'Albufera del Palmar, C.P. L'Assut de Fortaleny, C.P. La Molinà d'Almussafes, C.P. Granoters de Sollana, C.P. La Xopera d'Algemesí y Club Excursionista Alginet. Esta plataforma achaca la mortandad de peces a la pudrición de la paja del arroz en el lago, proceso que produce metano y quema el oxígeno del agua. Han llevado
} 
pudrición de la paja del arroz en el lago, proceso que produce metano y quema el oxígeno del agua. Desde esta plataforma se critica a la Administración por no dar una solución y dejar que la paja se pudra en el lago creado así un grave problema ecológico.

Desde su comienzos las áreas protegidas, se han asentado en políticas diseñadas 'desde arriba', que se basan en el modelo vertical top-down caracterizado por la primacía del conocimiento científico-técnico sobre el saber popular. Aparece aquí una nueva jerarquización, la del conocimiento, entre los que saben y no saben, es decir, entre expertos y locales; mientras que unos miran a los 'otros' como ignorantes, los otros ven a los 'de fuera' con hostilidad ante la competición por los usos y recursos (Santamarina, 2009). La ordenación territorial se sustenta sobre criterios tecnoecológicos y, de esta manera, se borran los usos y la historia local. Resta decir que los usos de la población local también se han visto sustancialmente modificados y han sido subsumidos por el capital. Para el caso del "canyar" no es cierto que lo "tradicional" es que se quemara sino que se recogía y se utilizaba para hacer sillas, tal y como se explicita también en los discursos.

En la mayoría de carteles también aparece el logo del Ministerio de Medio Ambiente y Medio rural y de la Confederación Hidrográfica del Júcar. Estos organismos gubernamentales son quienes financian y administran la zona. Asimismo aparecen ONGs ambientalistas en concreto "Acció Ecologista Agró" y "Seo Bird Life" que son quienes gestionan esta Área de Reserva. Esta conjunción entre ONGs ambientalistas y administraciones públicas es común en muchas de las áreas protegidas contemporáneas

su queja a la Fiscalía y al Síndic de Greuges. En sus escritos, Albufera Viva recuerda que la paja del arroz así como las cañas solían quemarse, pero que la Unión Europea exigió otro sistema de eliminación de estos restos de la cosecha por razones medioambientales. Pero la opción de dejar que se pudra en el lago del parque protegido de L'Albufera ha creado "un grave problema ecológico" que se traduce en aguas negras, especialmente en los tancats, y peces muertos, insisten desde la plataforma. 
(West, Igoe y Brockington, 2006) así como la exclusión de los autóctonos. Tal y como argumenta Nygren (1998) el problema se produce porque las ONGs ambientalistas dependen en gran medida de la "división occidental entre naturaleza y cultura". Las ONGs presentan con frecuencia la naturaleza como un objeto estático, separado de los seres humanos. Por extensión, se presentan los efectos ecológicos de las actividades humanas - como parte de la cultura - como antinatural.

Por último, mencionar también la aparición de del logo de la empresa multinacional Carrefour, concretamente en el cartel número 4. También hemos visto el logo de esta empresa en otros carteles que no hemos incluido para el análisis. Precisamente, la empresa financia el "día de la biodiversidad mundial" curiosa paradoja si tenemos en cuenta que estás empresas multinacionales llevan adosados importantes costes medio ambientales. Una vez más vemos como se "parchean" las soluciones ambientales a través de la participación en áreas protegidas. Siguiendo a Igoe (2010) observamos como la conservación de la biodiversidad y el capitalismo cada vez están más entrelazados. La triada ONGs ambientalistas, administraciones públicas y empresas multinacionales se consagra para mercantilizar la naturaleza y adentrar-la en los circuitos de consumo. Como sostiene McAffe (1999) estamos vendiendo naturaleza para salvarla. La subsunción real de la Naturaleza por el capital se produce también al separar su consumo de los contextos en los que se enmarca. Resta por saber que quedara de la Albufera si sólo se centran en la protección de estas áreas de reserva.

\section{La sociohermeneutica de los discursos}

Las prácticas metodológicas utilizadas para el trabajo cualitativo de producción de discursos han sido el grupo de discusión y la entrevista en 
profundidad. Dichas prácticas cualitativas nos han permitido acceder a discursos colectivos diferenciados y obtener las diferentes representaciones sociales de esta Área de Reserva. Entre diciembre de 2009 y junio de 2010 se realizaron 13 entrevistas en profundidad ${ }^{16}$ a diferentes actores sociales del entorno del Tancat de la Pipa, desde responsables municipales, técnicos medioambientales, asociaciones ecologistas, comunidad académica, trabajadores industriales, trabajadoras del hogar, trabajadores autónomos, empresarios, así como representantes de los sectores tradicionales. El material empírico que se ha utilizado para captar las posiciones ideológicas se ha completado con el análisis de dos grupos de discusión ${ }^{17}$ :

Cuadro 2. Composición y descripción de los Grupos de discusión

\begin{tabular}{|l|l|}
\hline $\begin{array}{l}\text { Grupo 1: Usos instrumentales } \\
\begin{array}{l}\text { Sectores sociales con actividades tradicio- } \\
\text { nales o modernas alrededor del Tancat de } \\
\text { la Pipa }\end{array}\end{array}$ & $\begin{array}{l}\text { Grupo 2: Usos conservacionistas } \\
\text { Sectores sociales vinculados a la conservación } \\
\text { del P.N.de la Albufera }\end{array}$ \\
\hline Empresarios/as & $\begin{array}{l}\text { Comunidad Científica } \\
\text { Cazadores, Agricultores y Pescadores }\end{array}$ \\
$\begin{array}{l}\text { Trabajadores/as autónomos/as Ecologistas } \\
\text { Trabajadores/as de la Administración Pública } \\
\text { Universitarias/os }\end{array}$ & $\begin{array}{l}\text { Técos/as medioambientales de la admi- } \\
\text { nistración pública } \\
\text { Educadores/s ambientales }\end{array}$ \\
\hline
\end{tabular}

\footnotetext{
${ }^{16}$ La entrevista en profundidad es una práctica que permite, a través de la conversación entre el investigador y el informante, acceder al sentido social de la conducta del entrevistado o de su grupo de referencia. "El campo de actuación de la entrevista en profundidad es el habla, un constructor comunicativo del discurso, el cual aparece como respuesta a una interrogación difusa en una situación dual y conversacional. Es un proceso de determinación en un contexto, un proceso de organización de hechos y de representaciones" (Alonso 1998:77).

${ }^{17}$ El grupo de discusión (Ibáñez 1979) es una conversación socializada, que se diseña (Alonso 1998:96) sobre la base de la identidad social y de sus representaciones; siendo estas representaciones sociales las formas de conocimiento colectivamente elaboradas con una orientación práctica y actualizable, y que determinan la forma común en la que los grupos humanos interpretan su realidad y la de otros colectivos.
} 
Para el de análisis de los discursos hemos seguido la propuesta de Fernando Conde (2009) en su ya citado 'Análisis sociológico del sistema de discursos'. Una propuesta donde se sistematiza la mejor tradición del 'cualitativismo crítico' español. En cuanto al modelo teórico, hemos seguido la propuesta del cuadrado de la "modernización", de Alfonso Ortí (1994, 1996), el Ilamado 'cuadrado M'. Un modelo tipológico y topológico, basado en la complejidad del proceso de modernización en las sociedades capitalistas, que define la modernización como el desarrollo dialéctico total de las potencialidades de la industrialización, y que pone de relieve la estrecha interrelación entre los procesos sociales y los simbólicos en las dinámicas de cambio social. A su vez, proporciona una visión histórica y de conjunto respecto a los desequilibrios estructurales de la modernización española con períodos, donde un alto grado de 'modernización política', no ha tenido una correlativa 'modernización social'; y otros donde el progreso de la 'modernización social' no se ha correspondido con la modernización política. También nos han sido muy útiles las aplicaciones que de este modelo ha hecho el Colectivo IOÉ $(1995,1996)$. 
Cuadro 3. Posiciones frente al proceso de modernización, concepción del medio ambiente y forma de conocimiento dominante.

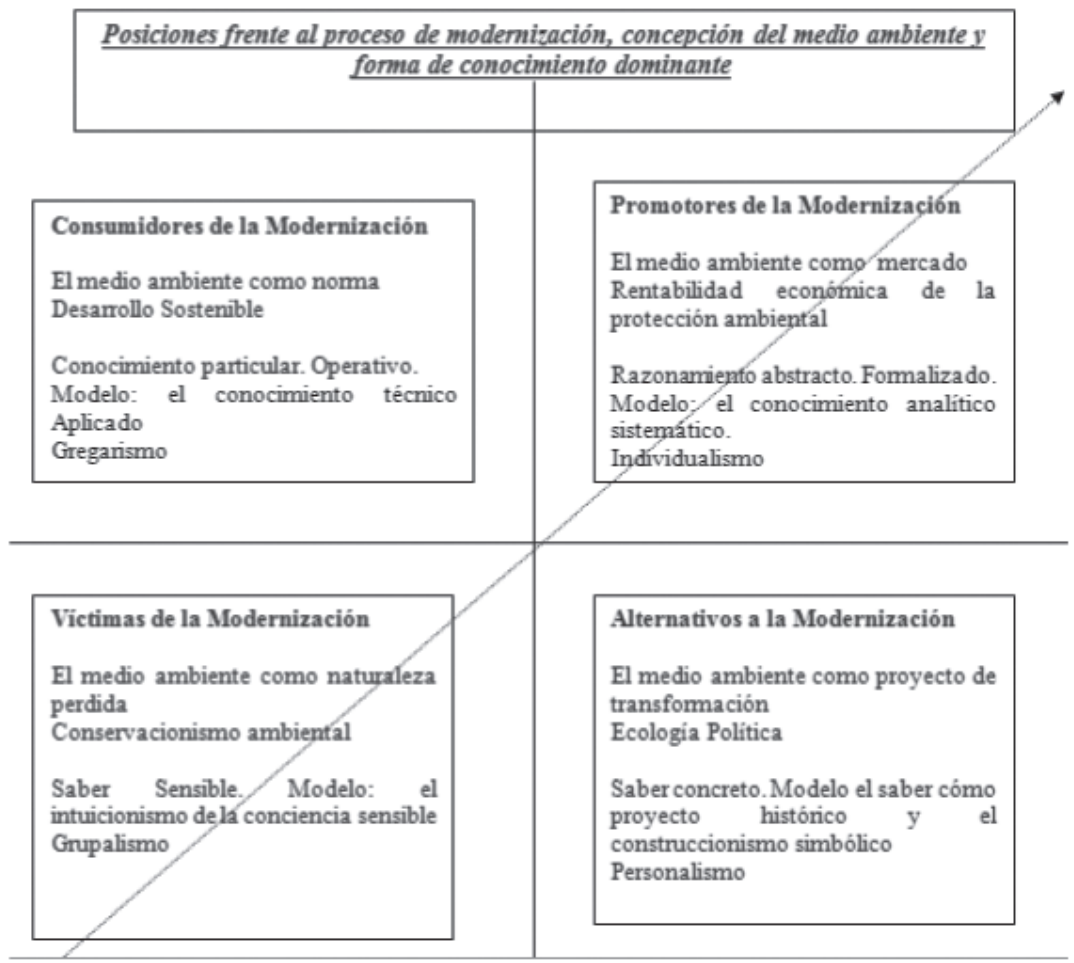

Fuente: Rodríguez Victoriano $(2002 ; 84)$

El cuadrado $\mathrm{M}$ se divide en dos ejes que dan lugar a cuatro cuadrantes o posiciones discursivas polarizadas entre sí. Entre las posiciones se dibujan cuadros de fuerza que permiten ubicar y explicar en un contexto significativo las posiciones concretas que adoptan los sujetos sociales para representar el Tancat de la Pipa y sus actitudes y valores respecto a él. El eje horizontal se tiende a caracterizar como el de la representación 
esquemática del proceso de cambio del mundo rural al mundo urbano que se ha desarrollado en paralelo al desarrollo capitalista (Conde, 2009). El eje vertical, en cambio, es el de atribución y medida del poder social en cada sociedad histórica. Poder social que en el caso de las sociedades occidentales capitalistas, se asocia con el incremento del poder tecnológico e institucional.

La posición de víctimas de la modernización está representada por los sectores tradicionales — cazadores, pescadores y arroceros. Desde esta posición, caracterizada por el saber sensible y el mundo rural, el Tancat de la Pipa se percibe como una expropiación de un espacio que les pertenece. La "recuperación" del espacio "natural" ha significado también el borrado sistemático del uso social de la zona. El Tancat de la Pipa eran 40 hectáreas de arroz en las que además se podía cazar y pescar. La eliminación física y simbólica del sector tradicional del paraje ha lleva adosado un sentimiento de hostilidad que ya venía generándose desde la declaración del Parque Natural de l'Albufera en 1986. Como ya se ha mencionado, desde sus inicios, las áreas protegidas se han caracterizado por políticas diseñadas desde arriba y por la imposición del conocimiento científicotécnico que menosprecia su saber de la experiencia (Rodríguez Victoriano, 2002). Si ya el conflicto entre técnicos medioambientales y el sector tradicional estaba presente en el Parque Natural, debido a la limitación de los usos tradicionales, está área de reserva viene a significar la purga de dichos usos. Bajo su parecer el Tancat se percibe como una embargo de su espacio: “(...) me está jodiendo a mí como cazador, me está jodiendo a mí porque de momento 200 metros ya no puedo cazar, en 200 metros ya no puedo cazar" (Entrevista cazador de Catarroja)

Los agricultores subrayan los daños en el cultivo que ha supuesto el aumento de aves. Sobre todo a partir de que la Generalitat Valenciana eliminara las ayudas agroambientales por la pérdida de cosecha. 
(...) [L]a Pipa está muy bien, es un hotel de cinco estrellas pero el que lo ha diseñado se ha olvidado de hacer el restaurante...ellos crían allí (se refiere a las aves) y comen en lo nuestro (se refiere a sus campos) (Entrevista concejal de agricultura y medio ambiente de Catarroja).

El conflicto es que hay muchos animalitos...entonces es lo que nos está haciendo a nosotros daño... hay una cantidad enorme de patos y cómo cada día se caza menos (...) nosotros ahora tenemos el problema del Calamón Común (Entrevista agricultor de Catarroja).

A pesar de que el discurso del sector tradicional no cuestiona las reglas de juego que ha mantenido la modernización económica capitalista, estos producen el discurso más crítico contra la protección oficial del medio. Puesto que entienden que esta protección les expropia lo poco que les quedaba de trato privilegiado con la naturaleza a la vez que les impone un saber técnico que relega su saber y los elige a ellos, como víctimas propiciatorias de una reconversión de la naturaleza que tolera las prácticas de destrucción de las industrias (Rodríguez Victoriano, 2002). No en vano, no debe olvidarse que los usos "tradicionales" han cambiado sustancialmente debido a la subsunción de la agricultura por el capital ${ }^{18}$ (Alonso, Arribas y Ortí, 1991).

\footnotetext{
${ }^{18}$ El proceso de universalización social de la mercancía supone el paso de una subsunción formal del campesinado bajo el capital - en la cual el capital subordina al campesino sobre la base de las mismas condiciones técnicas, sociales, personales y culturales que tenía tradicionalmente-, a una subsunción real del campesinado por el capital, en la que el capital recrea constantemente tanto las condiciones de trabajo como la forma de consumo de cara a la permanente acumulación de plusvalía relativa al conjunto de la economía global (Alonso, Arribas y Ortí 1991:38). De este modo, como sostiene Ortí (1992) subsumida plenamente la agricultura por el desarrollo capitalista transnacional, el mundo rural dejaría de contraponerse al mundo urbano. Con lo que las dramáticas luchas agrarias de la España contemporánea en torno a la propiedad y uso de la tierra habrían quedado subsumidas y superadas - mediante la expropiación y desarraigo final del campesinado tradicional - en un dilatado y conflictivo proceso de modernización, hecho sin duda necesario por las exigencias de la industrialización nacional, pero que habría tomado la forma (...final o transitoria) del pleno triunfo de la rentabilización capitalista transnacional ( Ortí, 1992; 245)
} 
Otra crítica que emerge del discurso de este sector radica en la hipocresía que les parece el proyecto del Tancat por la manera en la que se "construyó". Bajo el parecer de esta posición resulta hipócrita la prohibición del uso del espacio para usos "tradicionales" mientras que el proyecto fue construido con la ayuda de maquinarias de obra. Asimismo se destaca que está área no ayuda a resolver la degradación ecológica de la Albufera. Sin embargo los actores tradicionales enfatizan la utilidad del proyecto para la educación ambiental y las visitas turísticas sobre todo para la gente que no sepa lo que es la Albufera pues que venga y que vea allí que está bastante arreglado (Entrevista cazador de Catarroja).

Los consumidores de la modernización están representados por las clases medias y trabajadoras del mundo urbano y están caracterizados por un conocimiento particular ${ }^{19}$. Desde está poción discursiva el Tancat de la Pipa se presenta como un espacio de ocio para ser visitado y consumido en el sentido de parque temático. La clase media, harta de consumir las imágenes que reflejan la modernidad, está sedienta de consumir naturaleza así como las imágenes que esta proyecta. Tal y como se plantea desde esta posición el Tancat debe ofrecer esta demanda de consumo.

[A]demás yo se lo comentaba a ellas ( se refiere a las gestoras del Tancat): es que a esto le tenéis que hacer una labor de marketing importante... y quizás hacer un proyecto más abierto del que tenían previsto, porque ellas me planteaban el hacer algo más para (educación) secundaria, como más específico (...) y yo creo que haría un proyecto de más población, quiero decir por ejemplo hacer una conexión

\footnotetext{
${ }^{19}$ Desde esta posición se ve como compatible el crecimiento económico capitalista y la protección medioambiental. En España tiene una fuerte implantación. Uno de los últimos barómetros del Centro de Investigaciones Sociológicas sobre temas medioambientales indicaba que más del $50 \%$ de los encuestados afirma estar de acuerdo o totalmente de acuerdo que para poder proteger el medio ambiente se necesita crecimiento económico (estudio número 2954).
} 
que conecte con el Port de Catarroja, una ruta verde, una posible vista de familias un domingo (Entrevista Agente de Desarrollo Local Catarroja).

En este verbatim se expresan perfectamente la diferencia de demanda de consumo por parte de los consumidores de la modernización y la oferta que los gestores ofrecen del espacio. Además, como ya se ha comentado, la albufera es un signo histórico y culturalmente arraigado en la memoria colectiva de la sociedad valenciana. Todos los discursos, independientemente de la posición de la que se emanen, mitifican la idea de una Albufera como un paraíso que la modernización económica ha destruido.

Pues yo la he visto cambiar de ser un paraíso de agua ieh? Porque te ibas en las barcas a la albufera y te echabas nadando a la albufera (...) yo la vi cambiar desde el año, a ver...65 empezó a deteriorarse, montaron unas fábricas (...) y empezaron a echar toda la porquería (Entrevista pequeño empresario de Catarroja).

El Tancat de la Pipa ofrece los símbolos que caracterizan a esa imagen mitificada de la Albufera tan distinta de la que ahora ofrece este mismo espacio. De manera que, en el Tancat, no sólo se consumen imágenes de naturaleza sino que además, a través de esta zona, se consume identidad. Como se explicó en la parte teórica, la designación de un lugar como espacio protegido no sólo consiste en la replantación y preservación de especies vegetales o animales sino que implica la creación de una imagen cultural, una composición que puede ser construida como parte de la simbología local y, a su vez, las características de esa imagen hacen de estos espacios lugares idóneos para el consumo, se recrean como paisajes a contemplar.

Sin embargo, el proyecto del Tancat de la Pipa, es percibido por los locales -tanto por los representantes de la clase media y trabajadora como por el sector tradicional— como un algo desconocido y lejano tanto para el pueblo de Catarroja como para la sociedad valenciana en general. 
Dentro de los Alternativos a la modernización encontramos fracciones discursivas importantes que marcan la manera en la que se percibe socialmente el citado espacio. La primera fracción discursiva está representada por los movimientos ecologistas gestores de esta Área de Reserva, también se vinculan a esta posición los técnicos medioambientales del Parque Natural. El significado y la representación social que ofrece del Tancat de la Pipa para esta fracción es la imagen de un espacio que ha recuperado su condición idílica.

[L]o que hasta el año 2006 fueron campos de arroz, ha sido transformado en un Área de Reserva dentro del PN de l'Albufera con una variedad de hábitats característicos, con poca representación en la actualidad como marjales y un ullal (Extraído de http://www.tancatdelapipa.net/VenAlTancat.aspx el 28/06/2013).

Los discursos de estas posiciones se hibridan entre darle a la citada Área de Reserva un consumo científico así como un consumo culturaleducativo que implica visitas guiadas y controladas. Pero sobre todo se percibe el espacio como un lugar que favorece el aumento de la biodiversidad. Por todo ello, les parece una experiencia generalizable; olvidando de esta manera los usos tradicionales del espacio.

Claro es muy interesante...la albufera es muy grande(...) entonces cuantas más actuaciones se hagan en más zonas diferentes... ya no solo en la parte Saler, Palmar, ino?, sino que se empiecen a hacer actuaciones en otros sitios, aumentas la diversidad de hábitats siempre aumentarás biodiversidad y aumentas también lo que son las posibilidades de la gente para conocer otro tipo de ambientes, ¿no?, entonces está bien que la gente de Sollana pueda tener una zona para visitar por lo menos cerca de su pueblo, la gente de Catarroja, gente de Alfafar, gente de Silla... (Entrevista técnicos medioambientales del Tancat de la Pipa). 
Las últimas palabras del fragmento enfatizan los usos turísticos que desde este sector se le quiere dar a la zona. No en vano, siempre con carácter limitado y concertado previamente. Que, como ya se ha dicho, marca las diferencias entre el consumo demandado por la clase media y trabajadora y el que desde este espacio se ofrece.

Debido a la fragilidad ecológica del Tancat de la Pipa, se ha estimado una capacidad máxima de acogida de 60 personas, por lo que la entrada a la reserva ha de ser previamente concertada (Extraído de http://www.tancatdelapipa.net/VenAlTancat.aspx el 28/06/2013).

Resta decir que la zona cuenta con horarios de apertura y de clausura que junto con el tipo de visitas concertadas acentúan el carácter comercial del lugar —sin ánimo de lucro- a la vez que incrementan la sensación de que se perciba como algo ajeno para la población local.

Los movimientos ecologistas imbricados en el Tancat recuperan su posición política y crítica contra la administración pública y el desarrollo capitalista una vez salen de esta zona. De manera que tienen un discurso, una concepción y representación de la zona puertas hacia dentro del Tancat, donde trabajan como gestores, y otra puertas hacia fuera donde rescatan su posición política y activista en defensa de una Albufera que necesita mucho más que este tipo de proyectos para evitar su degradación ecológica.

La segunda fracción discursiva dentro de los alternativos a la modernización la encontramos en los discursos de los movimientos ecologistas y la comunidad científica que no están vinculados al Área de Reserva. Esta fracción cree que el proyecto está dentro de una lógica desarrollista, que no sacrifica la reducción de prácticas nocivas sino que las compatibiliza con el desarrollo económico — situando el proyecto dentro de la lógica del desarrollo sostenible.

Piensan que los conflictos ecológico-sociales de La Albufera sólo se pueden resolver si se producen cambios en el modelo de organización 
social —mostrando posturas cercanas al decrecimiento. Igualmente critican la obra dura que supuso el proyecto al que tachan de renaturalizado; una obra ingenieril que ha modificado el medio para la reproducción de la biodiversidad y que requiere un mantenimiento pero que ha olvidado cualquier connotación social.

(...) es un espacio renaturalitzado si se quiere... pero no es un espacio natural porque de hecho no funciona sin que el motor esté bombeando agua(...) no deja de ser un experimento y lo que pasa es que cada experimento tiene sus riesgos. Es pronto para decir, desde el punto de vista ecológico, en que acabará todo esto porque efectivamente es soportado (...) es ingenieril, tiene necesidad de la gestión no es una gestión como las otras orientada a la agricultura, sino a la recepción de aves (...) lo que pasa es que una vez has modificado las condiciones básicas del medio, cómo reacciona el resto de los elementos es impredecible (Entrevista investigadores de la UV y miembros de la Fundación Nueva Cultura del Agua y Xúquer Viu).

(...) cuando lo inauguraron yo fui a verlo y me decepciono porque claro vi allá un movimiento de tierra tan grande y pensé: "hombre que podían haber aprovechado un poco lo que ya había y esto, ¿no? (...)" Pero lo sorprendente es que hay demasiada transformación grande (...) claro yo habría hecho parcelas pequeñas, un poco experimentales e ir tirando, ¿no? Pero claro aquí pasan las máquinas y lo arrasan todo (...) Claro hacen obra dura y no sé y allá habían... aquí normalmente hay un árbol...el tamarix, que lo podrían haber dejado (...) pero lo arrasan todo (Entrevista catedrática de ecología).

A su vez, desde está posición, se destacan aspectos positivos tales como el contexto en el que se creó el Área de Reserva y la movilización social que se generó en torno al encauzamiento del Barranco del Poyo y la diferencia entre lo que hubiera podido ser el Tancat $3 / 4$ un abocinamiento de hormigón al final del cauce - y en lo que se ha convertido - una obra de restauración de hábitat. También destacan que es una muestra 
de la facilidad que tienen los sistemas acuáticos de regenerarse una vez eliminadas las presiones antrópicas.

De momento lo que ha habido es una recuperación rápida... que podría ser un elemento positivo para la diversidad de las aves. Esto podría llevarnos a pensar que, bueno, la albufera está muy mal, pero si eliminaremos las presiones esto rápidamente se recuperaría (...). De todas maneras, no es un ejemplo generalizable, en la medida en que es un sistema modificado artificialmente (Entrevista investigadores de la UV y miembros de la Fundación Nueva Cultura del Agua y Xúquer Viu).

En cambio, los cercanos a esta fracción destacan las potencialidades de este proyecto y otros parecidos (el Racó de l'Olla) para su consumo "educativo" y/o científico.

[H]acer este tipo de experimentos que son vistosos, que pueden tener una rentabilidad en términos (...) educativos o científicos, en la estación de anillamiento de aves y cosas de estas, pero con un alcance muy limitado (Entrevista investigadores de la UV y miembros de la Fundación Nueva Cultura del Agua y Xúquer Viu).

El hecho de que experiencias como la del Tancat de la Pipa no ayudan a resolver los problemas medioambientales de la Albufera junto con otorgarle al proyecto potencialidades para la educación ambiental, son dos puntos en los que convergen las opiniones de los consumidores de la modernización, las víctimas de la modernización y también esta fracción de los alternativos a la modernización. Ahora bien, el termino educación ambiental aplicado en la zona es discutible. Por una parte, las visitas del proyecto no generan ningún tipo de conciencia sobre la degradación del espacio. Por otra parte, dicho proyecto, tampoco otorga soluciones pertinentes a los problemas ambientales. Además, hay que recordar que se trata de un espacio que se mantienen de manera artificial, por tanto el proyecto carece de un mecanismo pedagógico que infunda la interac- 
ción dentro de los ecosistemas. En suma, el proyecto queda lejos de los objetivos de la Educación Ambiental y no ayuda a entender el entorno ni tampoco a formar una cultura conservacionista.

Como ya se ha aludido, la declaración de las áreas protegidas parte de legislaciones que inducen a la dicotomía naturaleza/cultura y se apoyan en un discurso de carácter científico-técnico que traduce e instituye una particular concepción cultural acerca de la naturaleza y de las relaciones que las sociedades humanas pueden establecer con ella. Partiendo de esta dicotomía cualquier proyecto de educación ambiental no tienen sentido, está escisión entre naturaleza y cultura hace desvincular la degradación medioambiental de cualquier acción humana. La pedagogía que se deriva del proyecto, por tanto, está centrada en trasmitir una imagen idílica que poco o nada tiene que ver con su contexto. Tal como planteábamos estos espacios quedan como museos "in situ". Mientras se destruye todo el entorno, el Tancat emergen como recuerdo de lo que algún día fue la Albufera. Se consume imágenes y a su vez identidad, una tradición reinventada, lejos de los trabajos del cultivo del arroz y lejos de hacer explícito cualquier conflicto ecológicosocial. Por tanto, tal y como definió Gaviria, el proyecto estaría enmarcado en la ideología clorofila, es decir una venta «de la naturaleza,... de una nostalgia del paraíso perdido, mezcla de bucólico- vegetal» (Gaviria, 1969; 59).

\subsection{El triángulo sémico: entre lo "natural", lo "cultural y lo "artificial"}

Para intentar captar las diferencias entre las fracciones discursivas de los alternativos a la modernización, nos ha sido de utilidad el triángulo sémico de Lévi-Strauss. Este triángulo sémico parte del triángulo culinario que elabora Lévi-Straus para analizar las estructuras de orden en las prácticas de la cocina. A través de este modelo la actividad culinaria pude 
inscribirse en el seno de un espacio semántico de tipo triangular cuyos polos serían lo crudo, lo cocinado y lo podrido. Este modelo inicial de triangulo alimentario se transformó en el triángulo sémico más conocido constituido a partir de los vértices de lo natural, lo cultural y lo artificial (Pereña, 1994 citado en Conde, 2009). En la práctica del análisis sociológico del sistema de discursos se ha transformado, el citado triangulo, en una estructura diacrónica

[que] entiende cada uno de los citados vértices como un posible nivel de "cristalización" de las distintas culturas sociales que coexisten en un momento histórico determinado, como un espacio de inscripción de las culturas sociales desde la perspectiva de su desigual nivel de "naturalización" en unos grupos sociales determinados, y que asume y postula la existencia de una relación dinámica entre todos y cada uno de los vértices del triángulo (Conde, 2009).

\section{EL. TRIANGULO SEMICO COMO DTHL DE ANLIISTS DE LOS} PROCESOS DE CAMBIO SOCIOCULTURAL ${ }^{\text {is }}$

Natural $(4+1)$

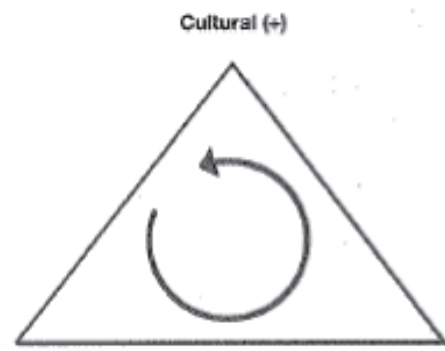

Artificial (-)

\footnotetext{
" Los signos + y - que acompantan al triángulo se refieren a las valoraciones sociales que suelen acompanar a cada vértice: más positivas en lo natural, positivas en el de lo cultural y mís polémicas, cuando no son directamente negativas, en el vértice o nivel de lo artificial.
}

Imagen 2. Triángulo sémico como útil de análisis de los procesos de cambio sociocultural. 
Para el caso de las representaciones que los distintos grupos sociales hacen del Tancat de la Pipa, podríamos argumentar que la primera fracción de los alternativos a la modernización citada - aquellos movimientos ecologistas implicados en la gestión del Tancat- verían el proyecto como algo natural. Siguiendo a Conde (2009) la noción de lo natural se interpreta como el nivel de integración de un objeto, de un fenómeno en la cultura de un grupo social que lleva a percibir y vivir dicho fenómeno como algo dado de forma casi natural en ese entorno cultural, como lo que siempre ha sido así, como lo dado de toda la vida. Así pues desde esta fracción discursiva, se percibe el Tancat de la Pipa, tal y como está ahora, como un espacio que ha recuperado su estado original, el estado que siempre ha tenido. Pero tal y como argumenta Nygren (1998) el problema de muchas ONGs ambientalistas radica en la división que estás establecen entre naturaleza y cultura. De esta manera, presentan la naturaleza como un objeto estático, separado de los seres humanos. Por extensión, las actividades humanas se presentan como algo antinatural.

En cambio, las víctimas de la modernización, vendrían a representar el Tancat como algo artificial, pues lo lo natural y lo de toda la vida para esta posición son los campos de arroz que habían en este espacio, antes de que se produjera la restauración de hábitats naturales. Por tanto, perciben el Tancat de la Pipa, tal y como está ahora, como algo extraño, ajeno (expropiado) y anómalo a su cultural.

La noción de lo 'cultural' siguiendo a Conde (2009) sería, a su vez, aquel nivel de integración más dinámico a caballo entre la 'naturalización' de lo natural y la 'extrañeza de lo artificial. Tras el análisis del discurso, bajo nuestro parecer esta sería la percepción que tiene la segunda fracción discursiva de los 'alternativos a la modernización' que entenderían el Tancat como un espacio renaturalizado. 
José Manuel Rodríguez Victoriano é professor e pesquisador da Universidade de Valencia, Espanha, no Departamento de Sociologia e Antropologia Social, tendo como interesse de pesquisa temas sobre meio ambiente, trabalho, ciência e tecnologia, entre outros. $>$ jose.m.rodriguez@uv.es

Marina Requena i Mora. Pesquisadora bolsista. Universidade de Valência, Espanha. $>$ marina.requena@uv.es

\section{Referencias}

1. ALMENAR, R.; BONO, E.; GARCÍA, E. La sostenibilidad del desarrollo: el caso valenciano. Valencia: Universitat de València/Fundació Bancaixa, 2000.

2. ALONSO, L. E. La mirada cualitativa. Madrid: Fundamentos, 1998.

3. BELTRÁN, O.; PASCUAL, J.; VACCARO, I. (coord.). Patrimonialización de la Naturaleza. El marco social de las políticas ambientales. Donostia: Akulengi Antropología Elkartea, 2008.

4. CALLEJO, J. Percepción de los problemas medioambientales por la población andaluza. Instituto de Estudios Sociales Avanzados de Andalucía /Consejo Superior de Investigaciones Científicas / junta de Andalucía: Andalucía, 1996.

5. COCA, A.; QUINTERO, V. Los de fuera claman naturaleza. ¿Qué claman los de dentro?. In: VALCUENTE DEL RIO, J.; CARDIA, L. Territorializaiçao, Meio Ambiente e Desenvolvimientono Brasil e na Espanha. Brasil, Universidade Federal do Acre, p.319-348, 2006.

6. CONDE, F. Análisis sociológico del sistema de discursos. Madrid: CIS, 2009.

7. FESTINGER, L. A theory of cognitive dissonance. Stanford, CA: Stanford University Press, 1957.

8. GARCÍA, E. El trampolí Faustic. Ciència, mite i Poder en el desenvolupament sostenible, valencia. València: Germania, 1995.

9. GARCÍA, E. Medio ambiente y sociedad. La civilización industrial y los límites del planeta. Madrid: Alianza Editorial, 2004

10. GARCÍA, E.; CABREJAS, M. Medio ambiente y conflicto social: El caso de la Albufera. Política y Sociedad, Madrid, n-23, p. 75-97, 1996.

11. GARCÍA, E.; CABREJAS, M. València, I'Albufera, L'Horta: medi ambient i conflicte Social. València: Universitat de València, 1997.

12. GARCÍA CANCLINI, N. Las culturas populares en el capitalismo. MéxiCo,D.F: Nueva imagen, 1982. 
13. GAVIRIA, M. La ideología clorofila. Revista de Ciencia Urbana, n. 4, 59-62, 1969.

14. HARVEY, D. The condition of postmodernity: An enquiryinto the origins of cultural change. Oxford: Blakwell, 1989.

15. HOBSBAWM, E.; RANGER, T. La invención de la tradición. Barcelona: Crítica, 2002.

16. IBÁÑEZ, J. Más allá de la sociología: el grupo de discusión: teoría y crítica. Siglo XXI. Madrid, 1979.

17. IGOE, J. The spectacle of nature in the global economy of appearances: Anthropological engagements withs the spectacular meditations of transnacional Conservation. Critique of Antropology, n. 30, v. 345, 2010

18. LASH, S.; URRY, J. Economies of signs and space. London: Routledge, 1994.

19. LOWENTHAL, D. El pasado es un país extraño. Barcelona: Akal, 1998

20. MCAFEE, K. Selling nature to save it? Biodiversity and green developmentalism. Environment and Planning D: Society and Space, n. 17, p. 133-154, 1999.

21. NYGREN, A. "Struggle over meanings: Reconstruction of indigenous mythology, cultural identity, and social representation." Ethnohistory, n. 45(1), p. 31-63, 1998.

22. ORTÍ, A. La Apertura y El Enfoque Cualitativo o Estructural: la Entrevista Abierta Semidirectiva y la Discusión de Grupo. In: FERRANDO, M. G.; ALVIRA, F.; IBÁÑEZ, J. (eds). El Análisis de la Realidad Social. Métodos y Técnicas de Investigación. Alianza Univesidad Textos. Madrid, 1986.

23. ORTÍ, A. Proceso de Modernización y ejes de desarrollo personal formativo: Del saber sensible al conocimiento Abstracto individualizado. La Coruña (Septiembre de 1998) VI CONGreso Español de Sociología, 1998.

24. PRATS, L. Antropología y patrimonio. Barcelona, Ariel. 1997.

25. RODRÍGUEZ VICTORIANO J. M. Los discursos sobre el medio ambiente en la sociedad valenciana (1996-2000). Quaderns de Ciències Socials, n. 8 València: Universitat de València, 2002.

26. SANTAMARINA, B. De parques y naturalezas. Enunciados, cimientos y dispositivos. En Revista de Dialectología y Tradiciones Populares, v. 64, n. 1, 2009.

27. SANZ, E. Identidad, montaña y desarrollo: los valles de Roncal, Salazar y Aezkoa. Vitoria. Gobierno Vasco, 2008. 
28. SPENCE, M. D. Dispossessing the Wilderness: Indian Removal and the Making of National Parks. New York: Oxford University Press, 1999.

29. URRY, J. The tourist gaze. Londres: Sage, 1990.

30. URRY, J. Consuming Places. Londres: Routledge, 1995.

31. VIVANCO, L. Spectacular quetzals, ecotourism, and environmental futures in Monte Verde, Costa Rica. Ethnology, n. 402, p.79-92, 2001.

32. WAGNER, J. The politics of accountability: an institutional analysis of the conservation movement in Papua New Guinea. Soc. Anal, n. 45(2), p.78-93, 2003.

33. WEST, P.; CARRIER, J. Getting away from it all? Ecotourism and authenticity. Curr. Anthropol., n. 45(4), p.483-98, 2004.

34. WEST, P.; IGOE, J.; BROCKINGTON, D. Parks and peoples: The social impact of protected áreas. Annual Review of Anthropology, n. 35, p. 251-277, 2006.

Recebido em: 17/09/2013

Aceite final: 09/12/2013 